\title{
SOCIEDADE PÓS-COLONIAL E REPRESSÃO FEMININA: LEITURA DE CONTOS DE MIA COUTO
}

\author{
Eduardo Garlet ${ }^{1}$
}

Ana Paula Teixeira Porto ${ }^{2}$

\begin{abstract}
Resumo: Este estudo contempla reflexões sobre os contos "As três irmãs" e "Saia Almarrotada", publicados na antologia $O$ fio das Missangas, do escritor moçambicano Mia Couto, com objetivo de discutir como se constrói a representação da sociedade pós-colonial e da condição feminina nessas narrativas. O estudo está amparado nos pressupostos da Literatura Comparada, Teoria Literária e Estudos de Pós-Coloniais. A análise sugere que os contos analisados representam paradigmas tradicionais da sociedade moçambicana e revelam condições de opressão feminina que são atreladas tanto ao contexto histórico e cultural africano quanto de resultados do processo colonizatório.
\end{abstract}

Palavras-Chave: História. Sociedade. Opressão feminina. Mia Couto. O fio das Missangas.

Abstract: This study includes reflections on the short stories "As três irmãs" and "Saia Almarrotada" published in the anthology $O$ fio das missangas, pubhished by Mia Couto, in order to discuss how to build a representation of postcolonial society and fermina condition in these narratives. The study is supported on the assumptions of Comparative Literature, Literary Theory and Postcolonial Studies. The analysis suggests that the tales analyzed represent traditional paradigms of moçambicana society and women's oppression reveal conditions that are linked to both the África historical and cultural context and the results of the colonization process.

Keywords: History. Society. Oppression female. Mia Couto. The string of beads.

\footnotetext{
${ }^{1}$ Acadêmico do Curso de Letras da Universidade Regional Integrada do Alto Uruguai e das Missões URI, Câmpus de Frederico Westphalen. Bolsista PIIC/URI. E-mail - edugarlett@hotmail.com

2 Professora orientadora do trabalho, docente do Cursos de Graduação em Letras e do PPG Mestrado em Letras da Universidade Regional Integrada do Alto Uruguai e das Missões - URI, Câmpus de Frederico Westphalen. E-mail - anapaula@uri.edu.br
} 


\section{Introdução}

Experiências sociais, culturais e históricas do período pós-colonial são representadas em diversas obras de natureza artística, dentre as quais as literárias produzidas em países de colonização portuguesa, como Moçambique, por exemplo. Nesse processo, narrativas representam uma sociedade em que o poder e o discurso são atrelados para convencer sobre uma suposta superioridade que os colonizadores, nesse caso os europeus, tentavam impor, evidenciando sua suposta superioridade intelectual sobre os colonizados, que eram vistos como pessoas inferiores.

Com intuito de melhor compreender essas peculiaridades da vida social, teorias e críticas pós-coloniais estudam o processo histórico de colonização implementado por povos europeus em outros continentes, analisando o impacto da colonização europeia nas antigas colônias até o século XX. No que condiz a esse período, é possível perceber que os colonizadores impuseram sobre o colonizado as representações europeias, dando origem a um novo sujeito colonial, que passou pelo processo de repressão e de marginalização sob as ideologias dos europeus. É sob essa perspectiva que Goms (2015), em "Crítica Pós-Colonial e o(s) Colonialismo(s) Europeu(s)", afirma que

Historicamente localizada, a crítica pós-colonial problematiza o processo histórico da colonização empreendida pela Europa nos demais continentes e efetua a leitura desconstrutora de textos colonialistas de diversas ordens (literários, científicos, filosóficos, políticos, jurídicos, jornalísticos, de cunho religioso, etc.), neles destacando as representações européias a respeito dos nativos nas/das colônias e a conseqüente fabricação do "sujeito" colonial. A par disso, a crítica pós-colonial examina a produção de contradiscursos também de diversas ordens que expressam, ostensiva ou camufladamente, projetos de resistência do colonizado e suas estratégias de revide na árdua luta pela autonomia (GOMES, 2015 [s.p]).

Nesse processo de colonização, segundo a pesquisa da autora, as mulheres constituem figuras importantes. Sobre elas, estabeleceu-se uma relação de sujeito, representada pelo colonizador, e objeto, cabível a elas, pois os discursos autoritários 
eram fortemente disseminados para convencer sobre a inferioridade das mulheres e a necessidade de obediência delas ao comando masculino.

Os atributos dados aos homens, nas sociedades pós-coloniais, não eram dados às mulheres, pois, para Bonicci (2009) em "Teoria e Critica pós-colonialistas", o discurso pós-colonialista era impregnado pelo patriarcalismo e pela exclusividade sexista, o que consistia em jugar as mulheres, deixando-as subalternas, subjugadas e banalizadas.

A colonização e o discurso colonialista eram também impregnados pelo patriarcalismo e pela exclusividade sexista. $O$ termo homem e seus derivados incluíam o homem e a mulher; o mesmo privilégio não era dado ao termo mulher. A ideologia subjacente consistia, portanto, na junção das noções metrópole e patriarcalismo que estavam empenhadas em impor a civilização europeia ao resto do mundo. (BONICCI, 2009, p.263)

Thomas Bonnici (2009) também faz menção a teorias do discurso e do poder e salienta que as sociedades pós-colonialistas foram constituídas pela ideologia dominante dos europeus, onde gerações de homens tomava a mulher como uma figura inferior na sociedade, estabelecendo assim uma relação de sujeito e objeto sobre a figura feminina.

É evidente que o poder, com todas as suas consequências, é exercido para que surta máximo efeito possível. Gerações de europeus se convenciam da sua superioridade cultural e intelectual diante da "nudez" dos ameríndios; gerações de homens, praticamente de qualquer origem, tomavam como fato indiscutível a inferioridade das mulheres. Nesse caso, estabeleceu-se uma relação de poder entre o "sujeito" e o "objeto", a qual não reflete a verdade (BONNICl, 2009, p.257).

Desta maneira as sociedades que passaram pelo processo pós-colonial foram constituídas sob um regime patriarcal e conservador na qual as mulheres eram vistas como inferiores sobre os homens, destinadas a acatar o discurso de opressão e de repressão. No que tange ao processo colonizatório, as produções literárias também são importantes para representar a repressão e a opressão, compondo 
identidades para a figura feminina nas sociedades pós-coloniais, conforme afirma Bahriem "Feminismo e/no pós-colonialismo" ao destacar que:

Exemplares dessa perspectiva áreas como os estudos das mulheres e os estudos pós-coloniais surgiram em parte como resposta à ausência ou à indisponibilidade de perspectivas sobre as mulheres, as minorias raciais e as culturas ou comunidades marginalizadas em relatos históricos ou anais literários. Essa falta de representação é semelhante nas esferas política, econômica e legal. Aqueles/as "outros/as" no discurso dominante não têm voz ou dizer em suas representações; estão fadados/as, pelos que comandam a autoridade e os meios de falar, a terem quem "fale por" eles/as. Quando as minorias e outros são representados (BAHRI, 2013 [s.p]).

Para Borges (2010) essa representatividade, em obras literárias, é um reflexo da própria experiência social na qual o texto foi escrito, ou seja, a literatura é uma representação da sociedade, no período em que foi produzido, uma vez que essa representatividade se assemelha com a vida social dos sujeitos de determinados lugares. Segundo Borges, em "História e literatura: algumas considerações" (2010),

todo documento, seja ele literário ou de qualquer outro tipo, é representação do real que se apreende e não se pode desligar de sua realidade de texto construído pautado em regras próprias de produção inerentes a cada gênero de escrita, de testemunho que cria 'um real' na própria 'historicidade de sua produção e na intencionalidade da sua escrita' (BORGES, 2010, p. 96).

Obras literárias de países que têm a língua portuguesa como língua oficial em função de processos de colonização importa por Portugal buscam representar essa situação de opressão feminina. É o caso da antologia $O$ fio das missangas, publicada em 2009 por Mia Couto, na qual se encontram vinte e nove contos que tratam dos mais diversos temas, como: morte, violência, repressão, conservadorismo, vingança. 


\section{O fio das missangas e representação social}

Mia Couto, em O fio das missangas (2009), aborda as temáticas típicas do dia-a-dia, introduzindo em seu texto características da realidade social e humana, de modo geral a antologia passa a sensibilizar o leitor no momento em que tais características são postas em uma escrita poética típica de Mia Couto. Conforme Meloni (2010),

De maneira estrutural, $O$ fio das missangas, como o próprio título já aponta, é uma reunião de contos curtos, aparentemente esparsos, mas que conjugados se tornam em um imenso colar. Ao leitor passa a caber o papel de artesão que organiza as missangas narrativas deixadas pelo escritor, formando seu entendimento maior ao final do volume. E o resultado não poderia ser outro: um colar de emoções humanas que ultrapassam os limites do social com extrema sensibilidade poética (MELONI, 2010, p. 298).

Nessas narrativas as figuras femininas são exibidas como seres subalternos e marginalizadas, visto que são submetidas a passar servindo aos desejos e caprichos masculinos, abrindo mão de seus próprios anseios, sonhos e desejos femininos, e muitas das vezes humanos, como e pode perceber no trecho do $5^{\circ}$ conto da antologia, "Saia Alamarrotada":

Na minha vila, as mulheres cantavam. Eu pranteava. Apenas quando chorava me sobrevinham belezas. Só a lágrima me desnudava, só ela me enfeitava. Na lágrima flutuava a carícia desse homem que viria. Esse aprincesado me iria surpreender. E me iria amar em plena tristeza. Esse homem me daria, por fim, um nome. Para o meu apetite de nascer, tudo seria pouco, nesse momento (COUTO, 2009, $\mathrm{p}, 14)$.

Nesse fragmento a figura feminina, sem nome, aparenta levar uma vida degradante, permeada de tristeza e sofrimento, vida sobre a qual a personagem mesmo reflete - "só a lágrima me desnudava, só ela me enfeitava", devido às condições cotidianas impostas pelos personagens masculinos. Além disso, pode-se 
perceber a falta de identidade feminina da personagem, já que a protagonista não possui nome, assim como seus direitos, anseios e desejos, que retirados reprimidos.

É evidente que no decorrer dos contos percebe-se como as mulheres são tratadas pelos homens em $O$ fio das missangas, algo recorrente em boa parte dos textos dessa antolifa, e como a mulher é associada a um sujeito marginal, subjugada e silenciada, como Machado (2011) ressaltou ao referir-se sobre a antologia:

O universo feminino, através da ficção, com sensibilidade e sutileza, proporcionando um canal para que essas vozes silenciadas, esquecidas e condenadas à não-existência possam, de algum modo manifestarem-se. A sociedade ocidental foi construída sob um regime patriarcal e falocêntrico. Herdeira de uma tradição judaicocristã, a cultura sempre relegou a mulher uma posição marginal na sociedade; nesse sentido a mulher foi oprimida, subjugada, negada e silenciada (MACHADO, 2011, p. 06).

Ao estudar o contexto pós-colonial representado na antolgia, é notório que o período é permeado de um discurso autoritário, o que refletiu em uma sociedade em que as relações de poder eram totalmente desiguais, as mulheres nesse caso sofreram com a repressão e a colonização que ao mesmo tempo atingia tanto o homem quanto a mulher. Bonnici (2009, p.266), em seus estudos de Teoria e Critica Pó-Colonialistas, afirma que "se o homem foi colonizado, a mulher, nas sociedades pós-coloniais, foi duplamente colonizada", e estabeleceu-se assim a repressão sobre a mulher que, além de sofrer com esse período de colonização, sofria também com a repressão do discurso patriarcal que era fortemente autoritário.

Os contos "As três irmãs" e "Saia Almarrotada" são evidentemente textos que exemplificam essa condição feminina: ambos representam uma sociedade em que esse discurso, as relações de poder e o patriarcalismo subjazem qualquer outro tipo de poder que se estabeleceu neste período. As personagens apresentadas nesses dois contos são totalmente submissas aos homens com os quais convivem, no caso o pai e no segundo conto também o tio e os irmãos da personagem feminina. Ao mesmo tempo, há um silenciamento em suas vozes, já que não falam e então não conhecemos os seus discursos verbais, e ainda são reprimidas por homens que são 
de suas próprias famílias. Nesse entorno, é estabelecida essa condição patriarcal na vida das personagens, como será evidenciado na sequência destas reflexões.

\section{Análise dos contos: um olhar sobre a condição feminina}

Em "As três irmãs", o enredo é exposto de forma linear e contado a partir da voz de um narrador em terceira pessoa que se isenta de quaisquer comentários sobre os fatos relatados, sem fazer julgamento pessoal dos acontecimentos. $O$ narrador é onisciente neutro e no decorrer da narrativa acompanha o ponto de vista das três meninas.

No decorrer da história, o narrador não deixa exatamente claro o tempo em que o texto está sendo narrado, mas os acontecimentos reportam a uma época contemporânea, dado o enredo que constitui a história e a relação que pode ser estabelecida entre o conto e a sociedade africana.

As mulheres africanas nesse contexto sofrem com a opressão feminina, como mostra a relação das meninas com o pai Rosaldo, que é autoritário. Isso permite entender, segundo a leitura de Borges (2010), que a sociedade contemporânea representada no conto é totalmente conservadora e que nela havia a subordinação e a humilhação, mulheres eram criadas a fim de cuidar dos lares, o que pode ser observado no quanto às tarefas que as personagens exerciam - uma bordadeira, outra poetisa e outra cozinheira - serviam para suprir as necessidades de saudade, frio e fome do pai.

As figuras femininas nesse conto são personagens oprimidas pelo pai, que não leva em consideração os próprios sentimentos das filhas, e consequentemente elas não tiveram nenhuma perspectiva em suas vidas, como se o próprio tempo delas não tivesse existido, "[...] pois, as irmãs nem deram conta do seu crescer: virgens, sem amores nem paixões. " (COUTO, 2009, p. 04). Nesse fragmento do conto, podemos perceber que os fatos narrados, representam novamente uma sociedade conservadora, na qual as personagens femininas se assemelham as mulheres africanas de antigamente, tempo em que não podiam se satisfazer 
sexualmente, e que seus desejos e perspectivas eram de certa forma reprimidos (BORGES, 2010).

As personagens nesse conto podem ser apresentadas como personagens subalternas, pois as três irmãs não possuem nem vez e nem voz em suas vidas, já que foram criadas pelo comando autoritário do pai, que se isolou para bem longe, como reitera o narrador: "Eram três: Gilda, Flornela e Evelina. Filhas do viúvo Rosaldo que, desde que a mulher falecera, se isolara tanto e tão longe que as moças se esqueceram até do sotaque de outros pensamentos" (COUTO, 2009, p. $5)$.

Há também um conflito interno entre as três personagens femininas, já que elas foram criadas e modeladas a fim de cuidar das atividades domésticas e a se submeterem às ordens patriarcais. Tais conflitos estão relacionados à falta de direito de suas próprias escolhas, sendo obrigadas a servir e a passar o resto da vida aos cuidados do pai, o que se relaciona com a opressão feminina e consequentemente a uma sociedade conservadora, sendo que a voz para comando é unicamente a do pai.

No conto "As três irmãs", a ausência da voz feminina e o comando paterno confirmam a opressão que as figuras femininas sofreram, como confirma o narrador no começo do conto ao relatar o destino traçado por Rosaldo para elas: a de "serem filhas exclusivas e definitivas. Assim postas e não expostas, as meninas dele seriam sempre e para sempre. Suas três filhas, cada uma feita para um socorro: saudade, frio e fome." (COUTO, 2009, p.4).

Ao final do conto, o narrador apresenta outro personagem masculino, fazendo com que as personagens femininas estremecessem, fazendo-as perceber o quão não viveram: "Mas eis: uma súbita vez, passou por ali um formoso jovem. E foi como se a terra tivesse batido à porta de suas vidas. Tremeu a agulha de Evelina, queimou-se o guisado de Flornela, desrimou-se o coração de Gilda. " (COUTO, 2009, p.4). Rosaldo demonstra, mais uma vez o seu autoritarismo e seu egoísmo sobre as meninas, já que faz o que for possível para que a outra figura masculina não levasse suas filhas, como reitera narrador: "Logo-logo, as irmãs notaram o olhar toldado do pai. Rosaldo não tirava atenção do intruso. Não, ele não levaria as suas 
meninas! Onde quer que o jovem vagueasse, o velho pai se aduncava, em pouso rapineiro. " (COUTO,2015, p. 06)

Essa relação, autoritária e opressiva que Rosaldo tem com as filhas, está relacionada ao que explica a crítica pós-colonial de Bonnici (2009, p.259) para quem "Os textos surgidos das sociedades pós-colonialistas são transformados pelo contexto ou interpretação; portanto, é altamente carregado pela ideologia dominante, que exclui e degrada qualquer outro discurso". Essa representação no conto da relação do pai com as filhas ratifica a ideia da mulher ser considerada para fins do lar, e o homem no controle e comando da família, sendo o homem o "dominante" do lar, bem como o conto apresenta.

O ápice do conto é quando se percebe a ambiguidade que gira em torno de Rosaldo, personagem que é representado como uma figura conservadora e que demonstra uma possível relação homossexual com o jovem, que viera a aparecer no mesmo ambiente em que a família residia, como é possível perceber no seguinte trecho:

As três irmãs correram, furtivas, entre as penumbras e seguiram a cena a visível distância. E viram e ouviram. Rosaldo se achegando ao visitante e lhe apertando os engasganetes. A voz rouca, afogada no borbulhar do sangue: - Você, não se meta com minhas filhas! O moço, encachoado, rosto a meia haste. E ante o terror das filhas, o braço ríspido de Rosaldo puxou o corpo do jovem. Mas eis que o mundo desaba em visão. E os dois homens se beijaram, terna e eternamente (COUTO, 2009, p. 06).

Essa suposta relação homoafetiva entre os dois personagens pode ser lida também como uma tentativa de Rosaldo dizimar com a possível ideia da nova figura masculina levar suas filhas, e assim seriam submetidas a continuar servindo suas necessidades, mesmo que isso as deixasse infelizes para o resto da vida.

Lido sob esse viés, o conto "As três irmãs" representa a sociedade patriarcal e conservadora, uma Moçambique contemporânea que ainda constitui uma sociedade que oprime e reprime as mulheres e seus próprios direitos, pois o texto está inserido na sociedade moçambicana que é representada na obra como um todo. 
Quanto à temática da narrativa, pode-se perceber que ela não é exposta diretamente ao leitor, mas sim através da poética narração do autor, que atribui neologismos, que induz a pensar sobre o contexto moçambicano. Além disso, a forma como Mia Couto apresenta linearmente o texto e as personagens predispõe que essa representação de sociedade é continua, conforme explicita Bombardelli em suas reflexões sobre o conto:

A temática da opressão feminina é arquitetada por meio de informações sobre a sociedade de Moçambique, as quais não são diretamente expostas, mas sim, através de prosa poética que cria uma narração recheada de neologismos e jogos de linguagem que remetem àquele contexto. Além disso, a opção por enredo linear e configuração similar das personagens induz à ideia de que tal representação social é contínua: representaria assim uma visão coletiva, mais universal e não particular (BOMBARDELLI, 2015, p. 93).

O "Saia almarrotada", texto que se fundamenta em uma linguagem de fácil acesso e em uma narrativa em primeira pessoa, apresenta de forma linear apesar de ocorrerem "retrocessos" no tempo através de passagens na memória da personagem feminina, as quais aludem a sua condição. Assim como em "As três irmãs", são evidenciados o patriarcalismo e a opressão aos seus direitos como ser humano, o que a possibilidade de ter uma perspectiva de vida e de suprir suas próprias necessidades são enaltecidos.

O enredo faz referência a uma personagem feminina, que como ela mesma reitera no conto, vive para fins de pranto, cozinha e pano. Essa mulher está a serviço dos homens da sua família, mas propriamente o pai o tio e os irmãos. Traz para a história a mesma lógica do conto "As três irmãs" ao salientar que as mulheres eram destinadas a acatar as ordens dos homens da família e servi-los. Segundo Neto (2011),

A narradora do conto, como as demais mulheres do livro, são almas destinadas à inexistência, ao esquecimento. A personagem foi educada do mesmo jeito das três irmãs do outro conto supracitado ("As três irmãs"), com o objetivo de ajudarem os homens da família 
quando fossem velhos e, assim, com esse destino, ocorre um movimento de restrição e de alijamento do corpo (NETO, 2011, p.11).

Já no começo da narração, há uma epígrafe: "O estar morto é uma mentira. O morto apenas não sabe parecer vivo. Quando eu morrer quero ficar morta."(COUTO, 2009, p. 13). Essa epígrafe remete aos sentimentos oprimidos da personagem africana, pois para ela, que não tem nem nome, é apenas alguém que nunca teve oportunidade de desfrutar das alegrias que a vida poderia Ihe proporcionar, porque sua condição feminina é direcionada a cuidar apenas e unicamente da satisfação dos homens da sua própria família. Isso remete novamente à referência de Borges (2010) sobre uma sociedade africana contemporânea no contexto pós-colonialista, a qual apresenta traços de conservadorismo e de repressão aos direitos das mulheres.

Em "Saia almarrotada" pode-se perceber que a personagem feminina traz consigo heranças da sociedade pós-colonial, que excluía a mulher como sujeito na sociedade e era associada como inferior se comparada aos homens, ou seja, a mulher era sempre deixada de lado, em decisões importantes, nas quais a intenção era sempre silenciar suas vozes. Adaylson Wagner Sousa de Vasconcelos (2014), em seu ensaio sobre o conto "Saia almarrotada", diz que o texto

[...] discute no seu âmago a cultura de excessos e castrações promovida pela sociedade ocidental patriarcal que, herdeira de uma dezena de preceitos judaico-cristãos, destina à mulher a margem social. O silenciamento, as opressões e a busca de liberdade são algumas das cicatrizes identificáveis quando a intenção maior é calar a voz feminina (VASCONCELOS, 2014, [S.P]).

Ainda Vasconcelos (2014) faz uma análise das situações em que a personagem protagonista é submetida, mexe com os seus sentimentos, uma vez que a personagem feminina observa as outras mulheres com perspectivas de vida diferentes da sua, e ainda ressalta que a ausência da mãe para a construção como indivíduo na sociedade: 
Desde os primeiros dizeres, a personagem, que em nenhum momento lhe é atribuído nome, demonstra as tristezas a ela destinadas. A incumbência com os serviços domésticos e a impossibilidade de sentir prazer, sem dúvidas, são situações que mexem com as suas razões. Esses elementos são desenvolvidos no conto e trazem implicações principalmente no plano psicológico. As satisfações que apenas são possíveis para 'as mulheres de fora' e a ausência da mãe perante a sua construção como indivíduo também são marcas fortes no seu discurso (VASCONCELOS, 2014, [s.p]).

A personagem de "Saia Almarrotada" não possui nome, porque, segundo a referência da personagem, "Minha mãe nunca soletrou meu nome. Ela se calou no meu primeiro choro, tragada pelo silêncio" (COUTO, 2009, p. 29). A ausência de nome da personagem não é gratuita: sua mãe passou pelas mesmas experiências e a vida da filha é uma continuidade do anonimato da mãe, como a personagem declara ao relatar que "Que o meu nome tinha tombado nesse poço escuro em que minha mãe se afundara" (COUTO, 2009, p.31).

A personagem feminina de "Saia Almarrotada" demonstra que as marcas que seu pai deixou internamente na maneira de como a criou, para o choro, a cozinha e o pano, excluíram a possibilidade da sua própria emancipação feminina, uma vez que, mesmo após a morte do pai, ela continua sem perspectivas de vida:

Chega-me ainda a voz de meu velho pai como se ele estivesse vivo. Era essa voz que fazia Deus existir. Que me ordenava que ficasse feia, desviçosa a vida inteira. Eu acreditava que nada era mais antigo que meu pai. Sempre ceguei em obediência, enxotando tentações que piripirilampejavam a minha meninice. Obedeci mesmo quando ele ordenou: - Vá lá fora e pegue fogo nesse vestido! (COUTO, 2009, p. 31-32).

Nesse fragmento, pode-se perceber que a autoridade e a opressão do pai, mesmo após ter falecido, exercem grande influência na maneira de como a personagem vive, restrita aos ensinamentos do pai, que egoísta insistia que a filha deixasse qualquer atividade que fosse para o benefício dela ou de suprir as necessidades que ela poderia ter para atribuir o seu tempo apenas aos cuidados e aos caprichos dos homens do seu lar. 
A personagem em "Saia almarrotada" foi degradada pelos homens de sua família, que, ao oprimi-la e obrigá-la a cuidar dos caprichos masculinos, fez com que a personagem perdesse possíveis perspectivas, assim a personagem mesmo reflete sobre sua condição de vida no seguinte trecho: "Agora, estou sentada, olhando a saia rodada, a saia amarfanhosa, almarrotada. E parece que me sento sobre a minha própria vida" (COUTO, 2009, p. 15). Vida essa que a personagem julgava ser tão insignificante que ela mesma "poderia sentar sobre sua própria vida".

Pode-se constatar que, ao usar o neologismo "almarrotada", que seria uma junção de alma e amarrotada, o narrador põe em evidência um traço singular da personagem, como se a alma dela fosse desconfigurada, sua vida sem destaque. Acentua assim a humilhação que ela sofreu durante a vida, a restrição que lhe foi imposta pelo pai e pelo tio e, como consequência, a vida de pouca graça e de pouco ânimo que a consagrou e estimulou a pôr fogo em si mesma.

\footnotetext{
Essa protagonista tem seu insight identitário quando o pai a manda queimar uma saia que, em sigilo, ganhou de seu tio. Ao invés de atear fogo na vestimenta, ela a enterra e lança-se à fogueira, mas, os irmãos a salvam. O conto termina com a protagonista levando o vestido para ser queimado, depois de desenterrá-lo e de o pai ter morrido (MACHADO, 2011, p. 07).
}

O final do conto, no qual a personagem desloca-se em direção a uma fogueira, insinua que a mulher prefere morrer a ser submetida aos caprichos que lhe são impostos assim como pela constante humilhação que a personagem sofre. Segundo o pensamento de Marlene Mendes (2012), a ordem anterior para que queimasse o vestido é como quem diz "esqueça sua vida" (MENDES, 2012, p. 87). Contudo, ela desobedece às ordens de seu pai e decide se jogar ao fogo, no qual as chamas não a queimavam, pois "[...] não eram chamas. Eram as mãos escaldantes do homem que veio tarde, [...]" (COUTO, 2009, p. 31p. 32). Ou melhor, o homem que nunca veio a salvar, a lhe dar uma outra vida.

\section{Considerações finais}


Os contos e analisados representam uma sociedade moçambicana como no caso das "Três irmãs" em que as personagens, como Flornela, Gilda e Evelina, são submetidas a opressão social e familiar. A descrição das personagens, sob um texto organizado didaticamente apresentando uma de cada vez, permitem a reflexão sobre como as personagens vivem e convivem no lar restrito, atribuindo a cada uma das irmãs serviços domésticos, uma cozinheira, uma petista e a outra bordadeira que serviriam para suprir as necessidades de um homem, o pai.

Em "Saia Almarrotada" o discurso autoritário e patriarcal dos personagens masculinos é exposto como uma voz celestial que nunca poderia ser contrariada. Assim só resta à personagem-narradora acatar as ordens masculinas e realizar as tarefas as quais são impostas a ela, mesmo que essas condições de vida lhe prejudicassem. Observa-se que a personagem não possuía nenhuma característica ligada ao feminino, posto que as características ligadas ao universo feminino a personagem concretizava em seu vestido enterrado.

A partir da leitura, pode-se concluir que os contos "As três irmãs" e "Saia almarrotada" representam uma sociedade contemporânea de Moçambique, que apresenta traços de conservadorismo e de patriarcalismo, posto que as mulheres são submetidas a acatar as ordens masculinas e a realizar tarefas domésticas. Além disso, são oprimidas e silenciadas pela sociedade de uma forma geral e pelas suas próprias famílias em particular, dando continuidade ao processo de subjugação da mulher.

\section{REFERÊNCIAS}

BAHRI, Deepika. Feminismo e/no pós-colonialismo. Rev. Estudos Feministas. Vol.21. Número 2. Florianópolis Maio , 2013. Disponível em <http://www.scielo.br/scielo.php?script=sci_arttext\&pid=S0104026X2013000200018 > acesso em: 13 de jan de 2017.

BOMBARDELLI, Daniela. Reflexões sobre opressão feminina e sociedade conservadora em contos de o fio das missangas, de mia couto. 2015. $101 \mathrm{f}$. Dissertação (Mestrado em literatura comparada) Universidade Regional Integrada,Frederico Westphalen, 2015. Disponível em <http://www.fw.uri.br/NewArquivos/pos/dissertacao/dis-92.pdf> Acesso em: 14 de jan de 2017. 
BONNICI, Thomas (org); ZOLIN, Lúcia Ozana (org). Teoria e Criticas póscolonialistas. In: Teoria Literaria: abordagens históricas e tendências contemporâneas. Maringá: Eduem, 2009.

BORGES, Valdeci Rezende. História e Literatura: Algumas Considerações. Revista de Teoria da História, Ano 1, n. 3, jun. / 2010. Disponível em: <http://www.historia.ufg.br/up/114/o/ARTIGO_BORGES.pdf> Acesso em: $11 \mathrm{fev}$. 2017.

COUTO, Mia. O fio das missangas. São Paulo: Companhia das Letras, 2009. GOMES. Heloísa Toller. Crítica Pós-Colonial em Questão. Z Cultural Revista do Programa Avançado em Cultura, Ano III, n.1, abr./2015. Disponível em: http://revistazcultural.pacc.ufri.br/critica-pos-colonial-em-questao-de-heloisa-tollergomes/. Acesso em: 13 fev. 2017.

MACHADO, Cristina Vasconcelos. Construção da representatividade feminina na obra $\mathrm{O}$ fio das missangas de Mia Couto. Anais do Simpósio Internacional Literatura, Crítica, Cultura V: Literatura e Política, realizado entre 24 e 26 de maio de 2011 pelo PPG Letras: Estudos Literários, na Faculdade de Letras da Universidade Federal de Juiz de Fora. Disponível em:

<http://www.ufjf.br/darandina/files/2011/08/Constru\%C3\%A7\%C3\%A3odarepresentat ividade-feminina-na-obra-O-fio-das-missangas-de-Mia-Couto.pdf.> Acesso em: 14 de jan. de 2017.

MELONI, Otavio Henrique. Um colar de experiências: o olhar cotidiano de Mia Couto em O fio das missangas. Caderno de Letras da UFF, Rio de Janeiro, v. 41, p. 297301, jun. 2010. Disponível em:

$<$ http://www.uff.br/cadernosdeletrasuff/41/resenha.pdf>. Acesso em: 10 fev. de 2017.

MENDES, Marlene. Uma missanga: uma mulher - uma perspectiva literário-jurídica.

Revista da Faculdade de Direito - UFPR, Curitiba, n.56, p.81-104, 2012.

MIRANDA, Maria Geralda de. Literaturas Angolana e Moçambicana: espelho da resistência e da disposição de construir um novo tempo. Disponível: <

http://apl.unisuam.edu.br/augustus/pdf/rev_augustus_ed\%2027_05.pdf > Acesso em: 10 fev. de 2017.

NETO, Pedro Fernandes Oliveira. O espaço da interdição em O fio das missangas, de Mia Couto. Nau Literária, Porto Alegre, v. 07, n. 02, jul./dez. 2011. Disponível em: <http://www.seer.ufrgs.br/NauLiteraria/article/download/20622/14059>. Acesso em: 9 de jan. de 2017.

VASCONCELOS, Adaylson Wagner Sousa de. A saia almarrotada, de Mia Couto, e O vestido, de Adélia Prado: a vestimenta como mecanismo de memória. Cadernos Imbondeiro, João Pessoa, v. 3, n. 2, 2014. Disponível em: <http://periodicos.ufpb.br/ojs/index.php/ci/article/view/21698/12824>. Acesso em: 9 fev. 2017. 
